\title{
Monocular syphilitic uveitis
}

\author{
Deirdre A Harford, ${ }^{1}$ Kit Green Sanderson, ${ }^{2}$ Kirk A J Stephenson (D) ,' \\ Conor C Murphy, ${ }^{1,2}$
}

${ }^{1}$ Department of Ophthalmology, Royal Victoria Eye and Ear Hospital, Dublin, Ireland ${ }^{2}$ Royal College of Surgeons in Ireland, University of Medicine and Health Sciences, Dublin, Ireland

Correspondence to Dr Kirk A J Stephenson; kirkstephenson@hotmail.com

Accepted 27 January 2021
Check for updates

(c) BMJ Publishing Group Limited 2021. No commercial re-use. See rights and permissions. Published by BMJ.

\footnotetext{
To cite: Harford DA Green Sanderson K, Stephenson KAJ, et al. BMJ Case Rep 2021:14:e241403. doi:10.1136/bcr-2020241403
}

\section{DESCRIPTION}

A 54-year-old woman presented with 7 days of monocular left blurred vision and floaters with best-corrected visual acuity (BCVA) of $6 / 15^{-2}$. She had no significant medical history. Headache was investigated elsewhere 4 weeks previously with negative temporal artery biopsy; however, temporal arteritis was treated empirically with oral steroids.

Examination showed $1^{+}$anterior chamber cells, intraocular pressure of $14 \mathrm{~mm} \mathrm{Hg}$, no cataract but dense central vitritis. A wedge-shaped area of temporal retina was outlined by white dot intraretinal infiltrates (figure 1A). Fundus fluorescein angiography (FFA, Optos plc, Scotland) showed nasal retinal vasculitis and diffuse temporal hyperfluorescence with obscured retinal vasculature (figure $1 \mathrm{~B}$ ) corresponding to the wedge-shaped area. Macular optical coherence tomography (OCT, Cirrus 5000, Carl Zeiss Meditec, USA) was normal (figure 1C). The working diagnosis was panuveitis with diffuse temporal retinitis and retinal vasculitis.

Serum and aqueous humour were negative for tuberculosis, Borrelia and Toxoplasma. Treponema pallidum rapid plasma reagin (RPR) serology was elevated at 1:256 prompting 14-day treatment with intravenous benzylpenicillin. Further investigations showed negative HIV serology, normal cerebrospinal fluid (CSF) analysis and cerebral vasculitis on neuroimaging. BCVA improved to 6/7.5 with reduction of vitritis and resolution of intraretinal infiltrates (figure 2A) leaving a large area of mottled hyperautofluorescence (figure 2B). OCT remained normal (figure $2 \mathrm{C}$ ).

Syphilis is a sexually transmitted infection with an estimated prevalence of $0.5 \%$ in adults $<50$ years. ${ }^{1}$ It accounts for $10 \%$ of infectious uveitis. ${ }^{2}$ Syphilitic uveitis (SU) typically denotes secondary syphilis; however,

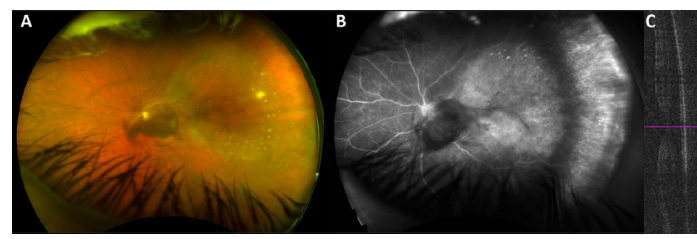

Figure 1 (A) Widefield colour photograph of the left fundus showing two clusters of central vitritis with wedge-shaped temporal area of abnormality surrounded by intraretinal white dots. (B) Late phase wide-field FFA of the left fundus showing nasal retinal vasculitis with a well-circumscribed temporal wedge-shaped area of hyperfluorescence; note, the intraretinal white dots are not uniformly apparent on FFA. (C) OCT image showing normal retinal structure with obscuration by vitritis artefact. FFA, fundus fluorescein angiography; OCT, optical coherence tomography.

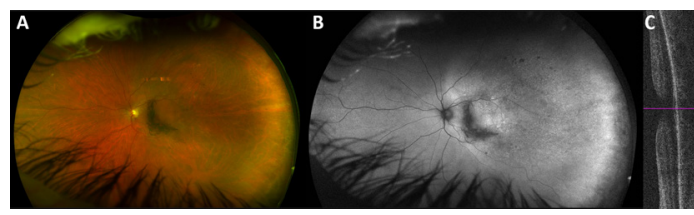

Figure 2 (A) Widefield fundus photograph of the left fundus 4 weeks after systemic antimicrobial treatment with dramatic improvement in vitritis, resolution of 'active' intraretinal white dots and development of fine round intraretinal pigmentation, indicative of resolved inflammation. (B) Widefield autofluorescence image showing a large temporal wedge of mottled hyperautofluorescence which is larger than the original clinically apparent extent of retinitis. (C) Optical coherence tomography showing preserved foveal outer retinal architecture, absence of macular oedema and clearing vitreous artefact.

ocular involvement may occur in any stage. ${ }^{1}$ Meningovascular syphilis manifests in 3\% of untreated syphilis infections comprising cerebral vasculitis with headache, motor/behavioural change or even stroke. ${ }^{3}$ 'The great imitator', ocular syphilis requires a high index of suspicion with myriad presentations including panuveitis (75\%), anterior uveitis (66\%), papillitis (88\%) and retinitis/vasculitis (72\%). ${ }^{145} \mathrm{SU}$ is bilateral in $>60 \%$, typically with HIV coinfection (70\%); thus, HIV testing in primary or secondary syphilis is prudent. ${ }^{5-7}$ Standard syphilis tests include screening by enzyme and chemiluminescent immunoassays, to detect antitreponemal antibodies, confirmed by the RPR test. ${ }^{5}$ Neurosyphilis manifests in $10 \%$ of untreated cases and SU should be managed as neurosyphilis (ie, CSF analysis, neuroimaging and therapy ${ }^{5}$ ). FFA and OCT are useful adjuncts assessing chorioretinal involvement (eg,

\section{Learning points}

- 'The great imitator:' a high index of clinical suspicion for syphilitic uveitis is good practice, particularly in high-risk cohorts (eg, HIV coinfection).

- Multimodal retinal imaging is useful in syphilitic uveitis to clarify the extent and severity of posterior segment inflammation as well as to monitor treatment response.

- Infective causes of uveitis (eg, T. pallidum, M. tuberculosis, B. burgdorferi) must be excluded prior to systemic immunosuppressive therapy as inappropriate immunosuppression may cause ocular or systemic deterioration. 
early phase FFA 'Leopard spotting' or hypofluorescent spots overlying acute syphilitic posterior placoid chorioretinal lesions ${ }^{6}$ ).

Parenteral penicillin (eg, intravenous benzylpenicillin or intramuscular procaine penicillin) is recommended for $10-14$ days $^{7}$ with cephalosporin/macrolide alternatives in penicillin-allergic individuals. Treatment success has been reported in up to $90 \%$ of cases. ${ }^{7}$ The Jarisch-Herxheimer reaction (ie, endotoxin-mediated systemic inflammatory response) occurs in up to $75 \%$ of patients after antimicrobial treatment of spirochaetal infections (eg, Treponema, Borrelia); thus, systemic steroids are appropriate to ameliorate these reactions. $^{8}$

Ocular syphilis is challenging due to its array of manifestations ${ }^{1245}$ with early diagnosis crucial as infection $>28$ days is associated with poor visual outcomes. ${ }^{6}$ This case is atypical as eye involvement was unilateral, cerebral vasculitis was seen, HIV test was negative and outcome was good despite delayed presentation.

\section{Twitter Conor C Murphy @OcularOirg}

Acknowledgements The authors would like to thank the Photographic Department of the Royal Victoria Eye and Ear Hospital, Dublin, Ireland.

Contributors DH and KGS: manuscript construction and revision. KAJS and CCM: diagnosis/clinical care, manuscript construction and revision.

Funding The authors have not declared a specific grant for this research from any funding agency in the public, commercial or not-for-profit sectors.
Competing interests None declared.

Patient consent for publication Obtained.

Provenance and peer review Not commissioned; externally peer reviewed.

Author note Twitter: Deirdre A Harford @DeirdreHarford; Kirk AJ Stephenson @ KarkStaphonsen; Conor C Murphy @OcularOirg

\section{ORCID iD}

Kirk A J Stephenson http://orcid.org/0000-0002-7462-7725

\section{REFERENCES}

1 Zhang T, Zhu Y, Xu G. Clinical features and treatments of syphilitic uveitis: a systematic review and meta-analysis. J Ophthalmol 2017;2017:1-15.

2 Bertrand P-J, Jamilloux Y, Ecochard R, et al. Uveitis: Autoimmunity... and beyond. Autoimmun Rev 2019:18:102351.

3 Behrouz R, Malek AR, Chichkova RI. Meningo-vascular syphilis: revisiting an old adversary. Pract Neurol 2011:32-7.

4 Shalaby IA, Dunn JP, Semba RD, et al. Syphilitic uveitis in human immunodeficiency virus-infected patients. Arch Ophthalmol 1997:115:469-73.

5 CDC Clinical Advisory. Ocular syphilis in the United States. Available: https://www.cdc. gov/std/syphilis/clinicaladvisoryos2015.htm [Accessed 07 Dec 2020].

6 Dutta Majumder P, Chen EJ, Shah J, et al. Ocular syphilis: an update. Ocul Immunol Inflamm 2019;27:117-25.

7 CDC. Syphilis treatment. Available: https://www.cdc.gov/std/tg2015/syphilis.htm [Accessed 07 Dec 2020].

8 Butler T. The Jarisch-Herxheimer reaction after antibiotic treatment of spirochetal infections: a review of recent cases and our understanding of pathogenesis. Am J Trop Med Hyg 2017;96:46-52.

Copyright 2021 BMJ Publishing Group. All rights reserved. For permission to reuse any of this content visit

https://www.bmj.com/company/products-services/rights-and-licensing/permissions/

BMJ Case Report Fellows may re-use this article for personal use and teaching without any further permission.

Become a Fellow of BMJ Case Reports today and you can:

- Submit as many cases as you like

- Enjoy fast sympathetic peer review and rapid publication of accepted articles

- Access all the published articles

Re-use any of the published material for personal use and teaching without further permission

Customer Service

If you have any further queries about your subscription, please contact our customer services team on +44 (0) 2071111105 or via email at support@bmj.com.

Visit casereports.bmj.com for more articles like this and to become a Fellow 